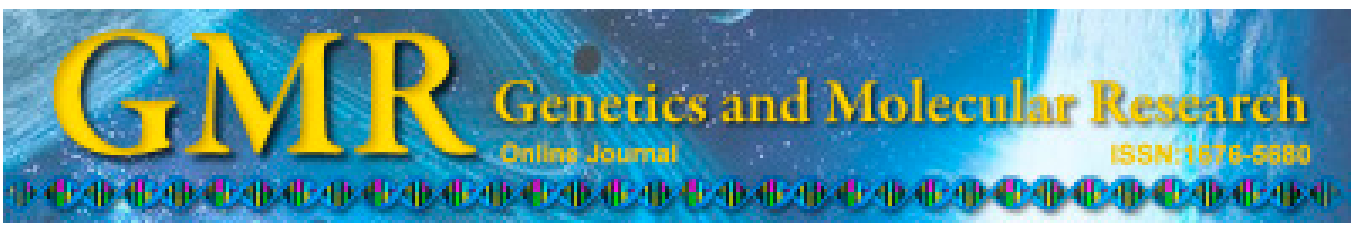

\title{
Cloning and association analysis of KIT and $E D N R B$ polymorphisms with dominant white coat color in the Chinese raccoon dog (Nyctereutes procyonoides procyonoides)
}

\author{
S.Q. Yan ${ }^{1}$, C.Y. Bai ${ }^{1}$, S.M. Qi ${ }^{2}$, M.L. Li ${ }^{1}$, S. Si ${ }^{1}$, Y.M. Li ${ }^{1}$ and J.H. Sun ${ }^{1,2}$ \\ ${ }^{1}$ College of Animal Science, Jilin University, Changchun, China \\ ${ }^{2}$ College of Animal Science and Veterinary Medicine, \\ Qingdao Agricultural University, Qingdao, China \\ Corresponding author: J.H. Sun \\ E-mail: jhsun0528@163.com
}

Genet. Mol. Res. 14 (2): 6549-6554 (2015)

Received October 1, 2014

Accepted February 23, 2015

Published June 12, 2015

DOI http://dx.doi.org/10.4238/2015.June.12.8

\begin{abstract}
The Chinese raccoon dog (Nyctereutes procyonoides procyonoides) is one of the most important fur-bearing animal species. The dominant white individual, a coat color variant in farmed Chinese raccoon dog, shows a completely white phenotype over the entire body. The KIT and EDNRB genes have been reported to be associated with the dominant white coat color in some mammalian species. In the present study, the full-length coding sequences of KIT and EDNRB were amplified from a dominant white and a wild-type Chinese raccoon dog. Sequence analysis revealed that the coding region of $K I T$ and $E D N R B$ in Chinese raccoon dog was 2919 and 1332 base pairs in length (accession No. KM083121 and KM083122), respectively, and 2 singlenucleotide polymorphisms (SNPs; c.600C $>$ T and c.967G $>$ A) in KIT and 1 SNP $(\mathrm{c} .259 \mathrm{~A}>\mathrm{C})$ in $E D N R B$ was found only in the dominant white individual. An alternative splicing site at the boundary of exons
\end{abstract}


4 and 5 of the KIT gene was identified in both individuals. We further investigated the association between the 3 SNPs of KIT and EDNRB and dominant white coat color by genotyping 18 individuals. We found no association between these SNPs and dominant white coat color. Based on these results, we can exclude the coding regions of the KIT and $E D N R B$ genes as determinants of the dominant white coat color in Chinese raccoon dog.

Key words: Chinese raccoon dog; Coat color; KIT gene; EDNRB gene; Polymorphisms

\section{INTRODUCTION}

The Chinese raccoon dog (Nyctereutes procyonoides procyonoides), which belongs to the family Canidae, is one of the most important fur-bearing animal species worldwide (Nowacka-Woszuk et al., 2013; Yan et al., 2013). The coat color is a key trait contributing to the economic value of its fur. The dominant white variant in farmed Chinese raccoon dog shows a completely white phenotype over the entire body (Figure 1), while the wild-type individual has a mixed coat color of black to brown with grey hairs (Han et al., 2012). Dominant white individuals hold the greatest economic value because their fur can be dyed to nearly any color. The causative mutation of the dominant white coat color in Chinese raccoon dog is unknown. In mammals, dominant white coat color can result from mutations in the KIT and EDNRB genes (Hayashi et al., 1991; Marklund et al., 1998; Santschi et al., 1998; Haase et al., 2007; Yan et al., 2014). Thus, the purpose of this study was to sequence and analyze the coding sequences of these 2 candidate genes in Chinese raccoon dogs with 2 types of coat color phenotypes, and to further determine the association between the polymorphisms and the dominant white coat color in the Chinese raccoon dog.

(a)

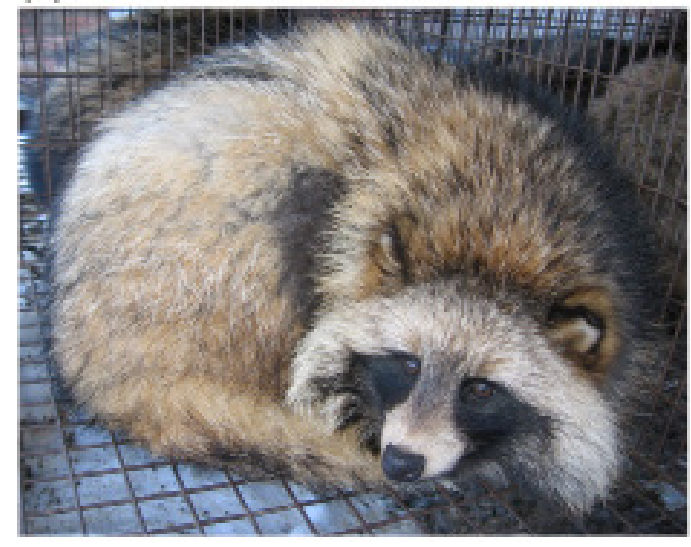

(b)

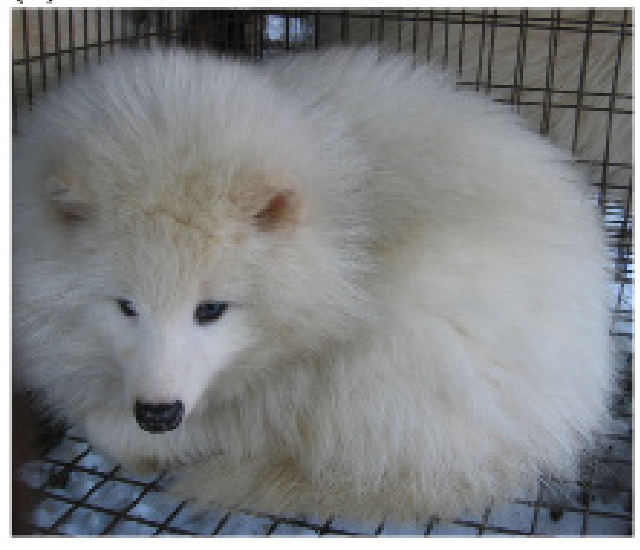

Figure 1. Coat color phenotypes of an adult wild-type (a) and dominant white (b) Chinese raccoon dog in winter. 


\section{MATERIAL AND METHODS}

Animal experiments were conducted in accordance with the guidelines on animal care established by the Jilin University Animal Care and Use Committee. The skin tissues were taken from 20 farmed Chinese raccoon dogs representing 2 types of coat color from 3 fur-bearing farms. Total RNA was extracted using the RNAprep pure Tissue Kit (TIANGEN, Beijing, China) according to the manufacturer protocol. First-strand cDNA was synthesized in $10 \mu \mathrm{L}$ reverse transcription solution containing approximately $0.2 \mu \mathrm{g}$ total RNA from each sample using PrimeScript ${ }^{\mathrm{TM}} \mathrm{RT}$ reagent Kit (TAKARA, Shiga, Japan) following manufacturer instructions.

According to the DNA sequences of canine KIT and EDNRB (accession No. NW_003726083 and NC_006604), 4 pairs of primers were designed using the Primer Premier 5.0 software (Premier BioSoft, Palo Alto, CA, USA) (Table 1). The cDNA of KIT and EDNRB was amplified using a nested-polymerase chain reaction (PCR) protocol. Primer pairs K1F/1R (or $\mathrm{E} 1 \mathrm{~F} / 1 \mathrm{R}$ ) and $\mathrm{K} 2 \mathrm{~F} / 2 \mathrm{R}$ (or $\mathrm{E} 2 \mathrm{~F} / 2 \mathrm{R}$ ) were used for the 1st and 2nd rounds of reverse transcription-PCR amplification, respectively. The 1st round of PCR amplification was performed in a volume of $25 \mu \mathrm{L}$ containing $0.5 \mu \mathrm{L}$ cDNA, $100 \mathrm{pM}$ of each primer, $0.2 \mathrm{mM}$ dNTPs, and $1 \mathrm{U}$ LA Taq polymerase (TAKARA). The PCR program consisted of $95^{\circ} \mathrm{C}$ for $3 \mathrm{~min}$, followed by 30 cycles of $94^{\circ} \mathrm{C}$ for $30 \mathrm{~s}, 60^{\circ} \mathrm{C}$ for $30 \mathrm{~s}$, and $72^{\circ} \mathrm{C}$ for $4 \mathrm{~min}$, and a final extension at $72^{\circ} \mathrm{C}$ for $15 \mathrm{~min}$. The 2 nd round of PCR was performed under the same conditions with the previous PCR products diluted by 1:10 as templates. The 2nd-round PCR products were sequenced directly, cloned into the pMD-19T plasmid vector (TAKARA), transformed into Escherichia coli $\mathrm{DH} 5 \alpha$, and then sequenced. Sequence analysis was performed using DNAMAN 5.0.

\begin{tabular}{lll}
\multicolumn{2}{c}{ Table 1. Sequences of primers used in this study. } \\
\hline Gene & Primer name & \\
\hline$K I T$ & K1F & Sequence $\left(5^{\prime} \rightarrow 3^{\prime}\right)$ \\
K1R & AACGGAGCTCCGGTCCCAG \\
K2F & CTCGTAAAGAGGGAGGGACAGA \\
K2R & AGCCACCGCGATGAGAGG \\
K3F & AGCCGAAGGAGGACAGAATAACCAG \\
& K3R & CAGAAGTGACCAATTACTCCCTC \\
E1F & CGACTGTGCCATTGTGCTTG \\
E1R & TCCTGTCTTTCTTCCCTTGCT \\
E2F & TGCTTCATGATGAGGCTTTCTTA \\
& E2R & CTTCCCTTGCTGGTCTCCAGACTC \\
& E3F & AGCACACAGTTGTTCGTTTGG \\
& E3R & TCACGACGCCTCCCACTG \\
& & TAGAGCGCATAGACTCAACACAG \\
\hline
\end{tabular}

Single nucleotide polymorphisms (SNPs) were identified according to the double peaks at the same position in the chromatogram by manual evaluation. In order to determine whether the 3 SNPs are involved in the dominant white coat color phenotype, reverse transcription-PCR amplification and a sequencing assay using the primer pair $\mathrm{K} 3 \mathrm{~F} / 3 \mathrm{R}$ (or $\mathrm{E} 3 \mathrm{~F} / 3 \mathrm{R}$ ) was carried out to genotype 18 individuals (9 for each type of coat color).

\section{RESULTS AND DISCUSSION}

The cDNA sequences of KIT and EDNRB were amplified successfully from the skin tissues of 2 individuals representing 2 types of coat color by nested-PCR amplification. The 
sequencing results revealed that the full-length coding sequences of KIT and EDNRB were 2919 and 1332 base pairs in length, respectively. The sequences were submitted to GenBank of the National Center for Biotechnology Information with accession No. KM083121 and KM083122. The mRNA sequences of KIT and EDNRB from Chinese raccoon dog were 99.0 and $98.9 \%$ similar with that of canine (accession No. AY313776 and NM_001010943), respectively.

According to the double peaks at the same positions in the sequencing chromatogram, 2 SNPs (c.600C $>$ T and c.967G $>$ A) in KIT and 1 SNP (c.259A $>$ C) in EDNRB were found only in the dominant white individual (Figure 2). The first SNP was a synonymous mutation, as it did not modify the encoded amino acid, while the others (c.967G $>$ A and c. $259 \mathrm{~A}>\mathrm{C}$ ) were missense mutations (p.323V $>$ I and p.87T $>$ P). In addition, an alternative splicing site, because of the NAGNAG splice acceptor sites at the boundary of exons 4 and 5 of the KIT gene, was identified and further confirmed by cloning and sequencing in both individuals (Figure 3). Two transcripts were designated as E and I, respectively, according to the description of Kim et al. (2011).

\section{(a)}

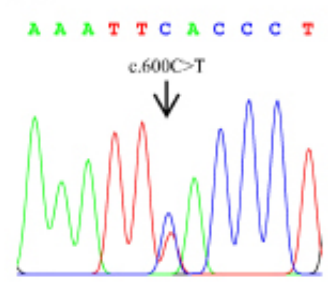

(b)
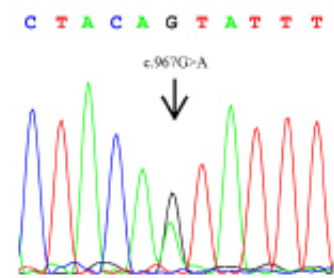

(c)

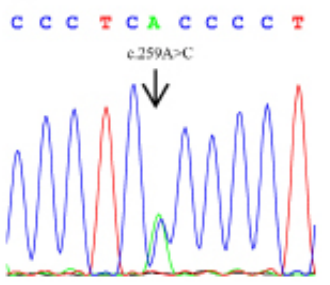

Figure 2. Single nucleotide polymorphisms (SNPs) found in the KIT and EDNRB genes of the dominant white Chinese raccoon dogs. a. and b. Partial chromatogram representing the 2 SNPs in KIT. c. Partial chromatogram representing the SNP in EDNRB.

(a)

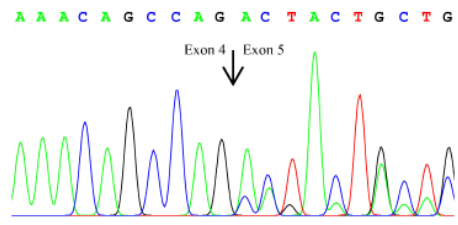

(b)

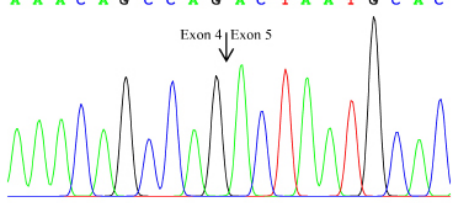

(c)

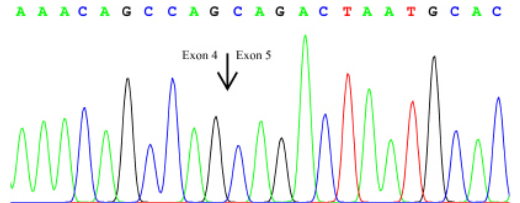

Figure 3. The chromatogram of $E$ and I transcripts resulting from the alternative splicing at the boundary of exons 4 and 5 of the KIT gene. a. Presence of both E and I transcripts. b. Isoform E. c. Isoform I. The arrows indicate the boundary of exons 4 and 5 , as well as the site of CAG insertion (c). 
Because 3 SNPs were exclusively found in the dominant white individual, we obtained additional genotype information for these SNPs in the remaining 18 individuals. The results indicated that 3 genotypes in the c.600C $>$ T and c. $967 \mathrm{G}>\mathrm{A}$ loci, and 2 genotypes (AA and $\mathrm{AC}$ ) in the c.259A $>\mathrm{C}$ locus were found in both dominant white and wild-type Chinese raccoon dogs (Table 2). Alternative splicing of the KIT gene was observed in individuals representing the 2 types of coat color; therefore, we excluded the association between the polymorphism and the dominant white coat color.

Table 2. Genotype of the KIT and EDNRB polymorphisms in the dominant white and wild-type Chinese raccoon dogs.

\begin{tabular}{|c|c|c|c|c|}
\hline Gene & SNP & Genotype & Dominant white individuals $(\mathrm{N})$ & Wild-type individuals $(\mathrm{N})$ \\
\hline \multirow[t]{6}{*}{ KIT } & c. $600 \mathrm{C}>\mathrm{T}$ & $\mathrm{CC}$ & 4 & 5 \\
\hline & & $\mathrm{CT}$ & 3 & 2 \\
\hline & & TT & 2 & 2 \\
\hline & c. $967 \mathrm{G}>\mathrm{A}$ & GG & 4 & 4 \\
\hline & & GA & 3 & 3 \\
\hline & & AA & 2 & 2 \\
\hline \multirow{3}{*}{$E D N R B$} & c. $259 \mathrm{~A}>\mathrm{C}$ & AA & 3 & 7 \\
\hline & & $\mathrm{AC}$ & 6 & 2 \\
\hline & & $\mathrm{CC}$ & 0 & 0 \\
\hline
\end{tabular}

In summary, the full-length coding sequences and a total of 3 SNPs and 1 alternative splicing pattern were identified for the KIT and EDNRB genes of Chinese raccoon dog. Genotyping analysis revealed that none of the polymorphisms was associated with the dominant white coat color. Whether there is a causative mutation in the non-coding regions of the KIT and EDNRB genes responsible for dominant white coat color of the Chinese raccoon dog requires further analysis.

\section{ACKNOWLEDGMENTS}

Research supported by projects of the National Natural Science Foundation of China (\#31072018) and the Fundamental Research Funds of Jilin University (\#200903332).

\section{REFERENCES}

Haase B, Brooks SA, Schlumbaum A, Azor PJ, et al. (2007). Allelic heterogeneity at the equine KIT locus in dominant white $(W)$ horses. PLoS Genet. 3: e195.

Han JI, Yang H, Jeung EB and Na KJ (2012). Altered expression of melanocortin-1 receptor (MC1R) in a yellow-coloured wild raccoon dog (Nyctereutes procyonoides). Vet. Dermatol. 23: 187-e37.

Hayashi S, Kunisada T, Ogawa M, Yamaguchi K, et al. (1991). Exon skipping by mutation of an authentic splice site of c-kit gene in $W / W$ mouse. Nucleic Acids Res. 19: 1267-1271.

Kim JH, Zhong T, Cho IC, Lim HT, et al. (2011). Characterization of an alternative splicing by a NAGNAG splice acceptor site in the porcine KIT gene. Genes Genom. 33: 179-186.

Marklund S, Kijas J, Rodriguez-Martinez H, Ronnstrand L, et al. (1998). Molecular basis for the dominant white phenotype in the domestic pig. Genome Res. 8: 826-833.

Nowacka-Woszuk J, Salamon S, Gorna A and Switonski M (2013). Missense polymorphisms in the MC1R gene of the dog, red fox, arctic fox and Chinese raccoon dog. J. Anim. Breed. Genet. 130: 136-141.

Santschi EM, Purdy AK, Valberg SJ, Vrotsos PD, et al. (1998). Endothelin receptor B polymorphism associated with lethal white foal syndrome in horses. Mamm. Genome 9: 306-309.

Yan SQ, Li YM, Bai CY, Ding XM, et al. (2013). Development and characterization of polymorphic microsatellite 
markers for Chinese raccoon dog (Nyctereutes procyonoides procyonoides). Genet. Mol. Res. 12: 6351-6355.

Yan SQ, Hou JN, Bai CY, Jiang Y, et al. (2014). A base substitution in the donor site of intron 12 of KIT gene is responsible for the dominant white coat colour of blue fox (Alopex lagopus). Anim. Genet. 45: 293-296. 